\title{
Análise econômica comparativa de empresas de água mineral quanto ao porte
}

\author{
Comparative economic analysis of mineral water \\ companies in relation to size
}

Thays de Souza João Luiz

Engenheira de Minas, Departamento de Engenharia de Minas e de Petróleo da Escola Politécnica da Universidade de São Paulo

E-mail: thaysouzaluiz@hotmail.com

\section{Daniel Henrique Ayres Rosa}

Engenheiro de Minas, Departamento de Engenharia de Minas e de Petróleo da Escola Politécnica da Universidade

de São Paulo

E-mail:pontocom@hotmail.com

\section{Antonio Stellin Júnior}

Prof. Dr., Departamento de Engenharia de Minas e de Petróleo da Escola Politécnica da Universidade de São Paulo E-mail: astellin@usp.br

\section{Resumo}

Esse trabalho faz uma análise econômica comparativa de três empresas de água mineral de pequeno, médio e grande porte, que estão localizadas no Estado de São Paulo. Todas as três empresas possuem as mesmas linhas de produção tais como copos, garrafas e garrafões. A análise será feita através da comparação entre os fluxos de caixa das três empresas.

Palavras-chave: Estado de São Paulo, análise econômica, fluxo de caixa, água mineral.

\section{Abstract}

This work makes a comparative economic analysis of a small-, medium- and large-sized mineral water company, the three of which are localized in the State of São Paulo. All have the same lines of production such as glasses, bottles and big bottles. The analysis involves the cash flow comparison of the three companies.

Keywords: State of São Paulo, economical analysis, cash flow, mineral water.

\section{Introdução}

O mercado de águas minerais de São Paulo é extremamente significativo no contexto nacional. Trata-se do maior mercado de águas minerais do país. O mercado brasileiro de águas minerais tem através do Estado de São Paulo, sua maior referência no crescimento de um mercado complexamente estruturado em relação aos demais Estados da Federação, conforme os dados estatísticos do anuário mineral do Departamento Nacional de Produção Mineral (DNPM), publicado no site oficial do mesmo no ano de 2009, tendo como ano-base o ano de 2008.

Com o intuito de analisar como o efeito de escala da produção influi nos fluxos de caixa dessas empresas, escolheram-se três empresas de portes distintos para se concluir a análise. 


\section{Material e métodos}

A análise econômica foi feita com base nos métodos de avaliação econômica de projetos de mineração como aqueles descritos em Souza (1995). Tal obra cita projetos de mineração mais complexos do que as empresas de água mineral.

Além disso, por se tratar de uma análise financeira, a metodologia clássica foi mantida, como se vê em Ross (2002). Foram feitas apenas adaptações para realidade e por se tratar de uma indústria mais simplificada, tal como a indústria de água mineral.

Como empresa de pequeno porte, foi escolhida a Empresa Água Mineral Santa Cândida Ltda., localizada no município de Mococa. Possuindo menos de 15 funcionários, é detentora de uma surgência e três poços; produz, mensalmente, 2.111.840 litros de água mineral, distribuídos nas linhas de copos, garrafas e garrafões.

Como empresa de médio porte, foi escolhida a Empresa de Mineração A\&M Ltda., localizada no município de São Paulo. Possuindo, aproximadamente, 60 funcionários, é detentora de três surgências e um poço; produz, mensalmente, 7.849.520 litros, distribuídos nas linhas de produção de copos, garrafas e garrafões.

Como empresa de grande porte ,foi escolhida a Spal Indústria Brasileira de Bebidas Ltda. (do Grupo da Coca-Cola), localizada no município de Mogi das Cruzes, na Grande São Paulo. Possuindo, aproximadamente, 100 funcionários, é detentora de dois poços. Produz, mensalmente, 12.153.832 litros, distribuídos em linhas de copos, garrafas e garrafões.

Serão analisadas as principais características operacionais de cada empresa e, depois, serão feitos os fluxos de caixa de cada uma, para posterior análise e futuras constatações. Pretende-se entender como o porte de cada empresa (levando-se em conta o fator escala de produção) influi no mercado e no próprio fluxo de caixa da empresa.

\section{Características principais das três empresas}

Os dados produtivos e operacionais principais de cada empresa são aproximados, pois oscilam ano a ano, mas se mantêm fiéis à realidade de cada mineração de água, sendo proporcionais ao seus respectivos portes. Os dados encontramse resumidos nas Tabelas 1 a 9.

\section{Resultados}

Para fazer os fluxos de caixa, foi utilizado o método dos períodos de recuperação do investimento - Payback ou Payout (PP), que consiste em calcular o número de períodos necessários à recuperação do investimento inicial. Os fluxos de caixa das empresas estudadas encontram-se descritos na Tabela $10 . \mathrm{Na}$ referida descrição, foram desprezados os centavos.

\section{Discussão}

Para se esclarecer como foram realizados os cálculos dos fluxos de caixa, é conveniente fazer as seguintes considerações:

- Os Custos Diretos são o somatório dos custos de mão-de-obra, dos custos de energia elétrica, dos custos de material de consumo (de copos, de garrafas e de garrafões), dos custos de transporte e dos custos de material de limpeza, higiene e laboratório.

- Os Custos Indiretos são a soma da depreciação (das construções civis, dos maquinários, dos equipamentos e dos veículos e do custo de manutenção dos equipamentos.

- Os Custos de Administração correspondem a $10 \%$ do somatório dos custos diretos mais os custos indiretos.

- Os Custos de Produção é igual à soma dos custos diretos, com os custos indiretos e com os custos de administração.
- A Receita Líquida é igual à receita bruta anual menos o custo de produção anual.

- Os Impostos e Taxas Sociais (I) são compostos pelo ICMS, COFINS/PIS (CP) e CFEM.

- O ICMS para comercialização da água mineral é de $18 \%$, logo o ICMS = receita bruta anual x 0,18.

- O COFINS foi considerado como $4 \%$ da receita bruta anual e o PIS, como $0,65 \%$ da receita bruta anual, logo, o COFINS/PIS $(\mathrm{CP})=$ receita bruta $\mathrm{x}$ 0,0465 .

- O CFEM é a compensação financeira, "royalt", a ser paga ao governo pela exploração comercial do bem mineral, correspondendo ao valor de $2 \%$ da receita bruta anual menos ICMS, COFINS e PIS, ou seja: CFEM= [receita bruta - (COFINS/PIS + ICMS)] x 0,02.

- Os Impostos e as Taxas Sociais correspondem a (I) = ICMS + COFINS/ PIS + CFEM.

- A Taxa de Retorno do Investimento (\%) corresponde a (Saldo de fluxo) $\div$ (investimento) x 100 .

- O Lucro Tributável é igual à receita líquida menos os impostos e taxas sociais (I).

- A Alíquota do Imposto de Renda é calculada sobre o lucro tributável.

- Para o cálculo do Imposto de Renda, utilizou-se a Tabela 11.

- O Lucro Líquido é igual ao lucro tributável menos a alíquota do imposto de renda.

Esse não se trata do único método de se fazer um fluxo de caixa, mas foi o método escolhido por ser o mais didático e mais simplificado.

Por meio da comparação dos três fluxos de caixa, as empresas vão ser avaliadas economicamente, observando o efeito "escala da produção" sobre o mercado e sua relação com o porte de cada empresa. 
Thays de Souza João Luiz et al.

\section{Conclusões}

Todos os empreendimentos estudados são economicamente viáveis para as três empresas do ponto de vista econômico, porque retornam o valor investido ao longo dos anos e produzem lucro.

A Empresa Água Mineral Santa Cândida Ltda. tem a menor produção, por ser uma empresa de pequeno porte, apresenta o menor lucro líquido e o retorno do investimento dá-se a partir do $6^{\circ}$ ano. Possui, ainda, as menores taxas de retorno. Os custos de produção são 14 vezes o valor do lucro líquido e a empresa demorará mais de 20 anos para ter um saldo de fluxo maior que os custos de produção, se mantiver a mesma produtividade.

A Empresa de Mineração A\&M Ltda. tem uma produção média, por se tratar de uma empresa de médio porte, apresenta lucro líquido com valor intermediário entre os valores da Empresa Santa Cândida Ltda. e da SPAL Indústria de Bebidas Ltda. Os Custos de produção são, aproximadamente, o dobro do lucro líquido e a empresa demorou dez anos para que o saldo do seu fluxo de caixa superasse em 4,6 vezes seus custos de produção, mantendo a mesma produtividade.

A empresa SPAL Indústria de Bebidas Ltda. tem uma grande produção em comparação com as demais, por se tratar de uma empresa de grande porte. Apresenta o maior lucro líquido entre as três empresas e o retorno do investimento dá-se a partir do quarto ano, mas esse fato deve-se ao investimento ter sido dezesseis vezes mais alto que a Empresa Santa Cândida e oito vezes mais alto que a Empresa de Mineração A\&M. Logo o retorno do investimento foi um pouco demorado. Os custos de produção são, aproximadamente, 20 vezes maior que o lucro líquido. Mas a empresa tem condições de fazer com que o saldo de fluxo supere os custos de produção em, aproximadamente, 20 anos, se mantiver a mesma produtividade.

Para a Empresa Água Mineral Santa Cândida, faz-se necessário o aumento da produção, para que a receita e
Tabela 1 - Comercialização dos produtos. Preço médio para a Empresa Água Mineral Santa Cândida.

\begin{tabular}{c|c}
\hline Garrafões de 5 I (fardo com 2 unidades) & $\mathrm{R} \$ 4,00$ \\
\hline Garrafões de 10 I (1 unidade) & $\mathrm{R} \$ 0,70$ \\
\hline Garrafões de 20 I (1 unidade) & $\mathrm{R} \$ 0,90$ \\
\hline Fardos com 12 garrafas de $330 \mathrm{ml}$ & $\mathrm{R} \$ 3,30$ \\
\hline Fardos com 12 garrafas de $510 \mathrm{ml}$ & $\mathrm{R} \$ 2,90$ \\
\hline Fardos com 6 garrafas de $1500 \mathrm{ml}$ & $\mathrm{R} \$ 3,30$ \\
\hline Caixa com 48 copos de $200 \mathrm{ml}$ & $\mathrm{R} \$ 5,50$ \\
\hline Caixa com 48 copos de $300 \mathrm{ml}$ & $\mathrm{R} \$ 6,50$ \\
\hline
\end{tabular}

Tabela 2 - Faturamento da Empresa Água Mineral Santa Cândida Ltda.

\begin{tabular}{c|c|c}
\hline Embalagem & $\mathbf{N}^{\circ}$. de unidades vendidas & Valor em R\$ \\
\hline Garrafões de 5 I & 16.000 fardos & $64.000,00$ \\
\hline Garrafões de 10 I & 38.400 unidades & $26.880,00$ \\
\hline Garrafões de 20 I & 70.400 unidades & $63.360,00$ \\
\hline Garrafas de $330 \mathrm{ml}$ & 6.400 fardos com 12 unidades & $21.120,00$ \\
\hline Garrafas de $510 \mathrm{ml}$ & 3.200 fardos com 12 unidades & $9.280,00$ \\
\hline Garrafas de $1500 \mathrm{ml}$ & 9.696 fardos com 6 unidades & $31.998,00$ \\
\hline Copos de $200 \mathrm{ml}$ & 750 caixas com 48 unidades & $4.125,00$ \\
\hline Copos de $305 \mathrm{ml}$ & 800 caixas com 48 unidades & $5.200,00$ \\
\hline Subtotal/Mês & & $\mathbf{2 2 5 . 9 6 3 , 0 0}$ \\
\hline Total/Ano & & $\mathbf{2 . 7 1 1 . 5 5 6 , 0 0}$ \\
\hline
\end{tabular}

Tabela 3 - Dados para análise econômica da Empresa Santa Cândida Ltda.

\begin{tabular}{c|c}
\hline Investimentos & $\mathrm{R} \$ 680.009,00$ \\
\hline Custo de mão-de-obra & $\mathrm{R} \$ 203.309,60$ \\
\hline Produção em litros (anual) & 25.342 .080 \\
\hline Receita bruta & $\mathrm{R} \$ 2.711 .556,00$ \\
\hline Custos diretos & $\mathrm{R} \$ 1.580 .951,12$ \\
\hline Custos indiretos & $\mathrm{R} \$ 65.191,14$ \\
\hline Custo de produção & $\mathrm{R} \$ 1.875 .947,62$ \\
\hline Custo unitário de produção & $\mathrm{R} \$ 0,07 /$ litro
\end{tabular}


Análise econômica comparativa de empresas de água mineral quanto ao porte

Tabela 4 - Comercialização dos produtos. Preço médio para a Empresa de Mineração A \& M Ltda.

\begin{tabular}{c|c}
\hline Garrafões de 5 I (fardo com 2 unidades) & $\mathrm{R} \$ 4,00$ \\
\hline Garrafões de 10 I (1 unidade) & $\mathrm{R} \$ 0,70$ \\
\hline Garrafões de 20 I (1 unidade) & $\mathrm{R} \$ 0,90$ \\
\hline Fardos com 12 garrafas de $330 \mathrm{ml}$ & $\mathrm{R} \$ 3,50$ \\
\hline Fardos com 12 garrafas de $510 \mathrm{ml}$ & $\mathrm{R} \$ 3,10$ \\
\hline Fardos com 6 garrafas de $1500 \mathrm{ml}$ & $\mathrm{R} \$ 3,20$ \\
\hline Caixa com 48 copos de $200 \mathrm{ml}$ & $\mathrm{R} \$ 5,70$ \\
\hline Caixa com 48 copos de $300 \mathrm{ml}$ & $\mathrm{R} \$ 6,90$ \\
\hline
\end{tabular}

Tabela 5 - Faturamento da Empresa de Mineração A\&M Ltda.

\begin{tabular}{c|c|c}
\hline Embalagem & $\begin{array}{c}\mathbf{N}^{\circ} \text {. de unidades } \\
\text { vendidas }\end{array}$ & Valor em R\$ \\
\hline Garrafões de 5 I & $\begin{array}{c}52.800 \text { fardos com } \\
2 \text { unidades }\end{array}$ & $211.200,00$ \\
\hline Garrafões de 10 I & 105.600 unidades & $73.920,00$ \\
\hline Garrafões de 20 I & 105.600 unidades & $95.040,00$ \\
\hline Garrafas de $330 \mathrm{ml}$ & $\begin{array}{c}6.667 \text { fardos com } \\
12 \text { unidades }\end{array}$ & $23.334,50$ \\
\hline Garrafas de $510 \mathrm{ml}$ & $\begin{array}{c}2.666 \text { fardos com } \\
12 \text { unidades }\end{array}$ & $8.264,60$ \\
\hline Garrafas de $1500 \mathrm{ml}$ & $\begin{array}{c}10.666 \text { fardos com } \\
6 \text { unidades }\end{array}$ & $34.131,20$ \\
\hline Copos de $200 \mathrm{ml}$ & $\begin{array}{c}1.333 \text { caixas com } \\
48 \text { unidades }\end{array}$ & $7.598,10$ \\
\hline Copos de 305 ml & $\begin{array}{c}2.333 \text { caixas com } \\
48 \text { unidades }\end{array}$ & $16.097,70$ \\
\hline Subtotal/Mês & & $\mathbf{4 6 9 . 5 8 6 , 1 0}$ \\
\hline Total/Ano & $\mathbf{5 . 6 3 5 . 0 3 3 , 2 0}$ \\
\hline
\end{tabular}

Tabela 6 - Dados para análise econômica da Empresa de Mineração A\&M Ltda.

\begin{tabular}{c|c}
\hline Investimentos & $\mathrm{R} \$ 1.390 .000,00$ \\
\hline Custo de mão-de-obra & $\mathrm{R} \$ 675.552,80$ \\
\hline Produção em litros (anual) & 94.194 .240 \\
\hline Receita bruta & $\mathrm{R} \$ 5.635 .033,20$ \\
\hline Custos diretos & $\mathrm{R} \$ 2.056 .418,28$ \\
\hline Custos indiretos & $\mathrm{R} \$ 61.800,00$ \\
\hline Custo de produção & $\mathrm{R} \$ 2.330 .040,10$ \\
\hline Custo unitário de produção & $\mathrm{R} \$ 0,02 /$ litro \\
\hline
\end{tabular}

Tabela 7 - Comercialização dos produtos. Preço médio para a SPAL Indústria de Bebidas Ltda.

\begin{tabular}{c|c}
\hline Garrafões de $5 \mathrm{I}$ (fardo com 2 unidades) & $\mathrm{R} \$ 1,50$ \\
\hline Garrafões de $10 \mathrm{I}$ (1 unidade) & $\mathrm{R} \$ 4,00$ \\
\hline Fardos com 12 garrafas de $350 \mathrm{ml}$ & $\mathrm{R} \$ 4,50$ \\
\hline Fardos com 12 garrafas de $510 \mathrm{ml}$ & $\mathrm{R} \$ 5,00$ \\
\hline Fardos com 6 garrafas de $1500 \mathrm{ml}$ & $\mathrm{R} \$ 5,50$ \\
\hline Caixa com 48 copos de $310 \mathrm{ml}$ & $\mathrm{R} \$ 8,00$ \\
\hline
\end{tabular}

Tabela 8 - Faturamento da SPAL Indústria de Bebidas Ltda.

\begin{tabular}{c|c|c}
\hline Embalagem & $\begin{array}{c}\mathbf{N}^{\circ} \text {. de unidades } \\
\text { vendidas }\end{array}$ & Valor em R\$ \\
\hline Garrafões de 5 I & $\begin{array}{c}200.000 \text { fardos } \\
\text { com 2 unidades }\end{array}$ & $300.000,00$ \\
\hline Garrafões de 10। & 800.000 unidades & $3.200 .000,00$ \\
\hline Garrafas de $350 \mathrm{ml}$ & $\begin{array}{c}40.000 \text { fardos com } \\
12 \text { unidades }\end{array}$ & $180.000,00$ \\
\hline Garrafas de $510 \mathrm{ml}$ & $\begin{array}{c}10.000 \text { fardos com } \\
12 \text { unidades }\end{array}$ & $50.000,00$ \\
\hline Garrafas de $1500 \mathrm{ml}$ & $\begin{array}{c}20.000 \text { fardos com } \\
6 \text { unidades }\end{array}$ & $110.000,00$ \\
\hline Copos de 310 ml & $\begin{array}{c}8.000 \text { caixas com } \\
48 \text { unidades }\end{array}$ & $64.000,00$ \\
\hline \multicolumn{2}{c}{ Subtotal/Mês } & $\mathbf{3 . 9 0 4 . 0 0 0 , 0 0}$ \\
\hline \multicolumn{2}{c|}{ Total/Ano }
\end{tabular}

Tabela 9 - Dados para análise econômica da SPAL Indústria de Bebidas Ltda.

\begin{tabular}{c|c}
\hline Investimentos & $\mathrm{R} \$ 11.009 .100,00$ \\
\hline Custo de mão-de-obra & $\mathrm{R} \$ 3.423 .570,15$ \\
\hline Produção em litros (anual) & 145.845 .984 \\
\hline Receita bruta & $\mathrm{R} \$ 46.848 .000,00$ \\
\hline Custos diretos & $\mathrm{R} \$ 34.553 .841,73$ \\
\hline Custos indiretos & $\mathrm{R} \$ 753.289,38$ \\
\hline Custo de produção & $\mathrm{R} \$ 36.366 .345,04$ \\
\hline Custo unitário de produção & $\mathrm{R} \$ 0,24 /$ litro \\
\hline
\end{tabular}


Thays de Souza João Luiz et al.

Tabela 10 - Fluxo de caixa das empresas

Empresa Água Mineral Santa Cândida Ltda.

\begin{tabular}{|c|c|c|c|c|c|c|c|c|c|c|c|}
\hline Ano & 0 & 1 & 2 & 3 & 4 & 5 & 6 & 7 & 8 & 9 & 10 \\
\hline Investimentos & 680.009 & & & & & & & & & & \\
\hline Receita bruta & & 2.711 .556 & 2.711 .556 & 2.711 .556 & 2.711 .556 & 2.711 .556 & 2.711 .556 & 2.711 .556 & 2.711 .556 & 2.711 .556 & 2.711 .556 \\
\hline Custo de produção & & 1.875 .947 & 1.875 .947 & 1.875 .947 & 1.875 .947 & 1.875 .947 & 1.875 .947 & 1.875 .947 & 1.875 .947 & 1.875 .947 & 1.875 .947 \\
\hline Receita líquida & & 853.608 & 853.608 & 853.608 & 853.608 & 853.608 & 853.608 & 853.608 & 853.608 & 853.608 & 853.608 \\
\hline Impostos e taxas & & 656.115 & 656.115 & 656.115 & 656.115 & 656.115 & 656.115 & 656.115 & 656.115 & 656.115 & 656.115 \\
\hline Lucro tributável & & 197.493 & 197.493 & 197.493 & 197.493 & 197.493 & 197.493 & 197.493 & 197.493 & 197.493 & 197.493 \\
\hline Imposto de renda & & 67.147 & 67.147 & 67.147 & 67.147 & 67.147 & 67.147 & 67.147 & 67.147 & 67.147 & 67.147 \\
\hline Lucro líquido & & 130.345 & 130.345 & 130.345 & 130.345 & 130.345 & 130.345 & 130.345 & 130.345 & 130.345 & 130.345 \\
\hline Saldo de fluxo & & -549.664 & -419.319 & -288.974 & -158.629 & -28.284 & 102.061 & 232.406 & 362.751 & 493.096 & 623.441 \\
\hline Taxa de retorno (\%) & & $-80,83$ & $-61,66$ & $-42,49$ & $-23,32$ & $-4,15$ & 15 & 34,17 & 53,34 & 72,51 & 91,68 \\
\hline
\end{tabular}

Empresa de Mineração A\&M Ltda.

\begin{tabular}{|c|c|c|c|c|c|c|c|c|c|c|c|}
\hline Ano & 0 & 1 & 2 & 3 & 4 & 5 & 6 & 7 & 8 & 9 & 10 \\
\hline Investimentos & 1.390 .000 & & & & & & & & & & \\
\hline Receita bruta & & 5.635 .033 & 5.635 .033 & 5.635 .033 & 5.635 .033 & 5.635 .033 & 5.635 .033 & 5.635 .033 & 5.635 .033 & 5.635 .033 & 5.635 .033 \\
\hline Custo de produção & & 2.330 .040 & 2.330 .040 & 2.330 .040 & 2.330 .040 & 2.330 .040 & 2.330 .040 & 2.330 .040 & 2.330 .040 & 2.330 .040 & 2.330 .040 \\
\hline Receita líquida & & 3.304 .993 & 3.304 .993 & 3.304 .993 & 3.304 .993 & 3.304 .993 & 3.304 .993 & 3.304 .993 & 3.304 .993 & 3.304 .993 & 3.304 .993 \\
\hline Impostos e taxas & & 1.363 .508 & 1.363 .508 & 1.363 .508 & 1.363 .508 & 1.363 .508 & 1.363 .508 & 1.363 .508 & 1.363 .508 & 1.363 .508 & 1.363 .508 \\
\hline Lucro tributável & & 1.941 .484 & 1.941 .484 & 1.941 .484 & 1.941 .484 & 1.941 .484 & 1.941 .484 & 1.941 .484 & 1.941 .484 & 1.941 .484 & 1.941 .484 \\
\hline Imposto de renda & & 724.471 & 724.471 & 724.471 & 724.471 & 724.471 & 724.471 & 724.471 & 724.471 & 724.471 & 724.471 \\
\hline Lucro liquido & & 1.217 .012 & 1.217 .012 & 1.217 .012 & 1.217 .012 & 1.217 .012 & 1.217 .012 & 1.217 .012 & 1.217.012 & 1.217 .012 & 1.217 .012 \\
\hline Saldo de fluxo & & -172.988 & 1.044 .024 & 2.261 .036 & 3.478 .048 & 4.695 .060 & 5.912 .072 & 7.129 .084 & 8.346 .096 & 9.563 .108 & 10.780 .120 \\
\hline Taxa de retorno (\%) & & $-12,45$ & 75,1 & 162,66 & 250,21 & 337,77 & 425,32 & 512,88 & 600,43 & 687,99 & 775,54 \\
\hline
\end{tabular}

Spal Indústria Bebidas Ltda.

\begin{tabular}{|c|c|c|c|c|c|c|c|c|c|c|c|}
\hline Ano & 0 & 1 & 2 & 3 & 4 & 5 & 6 & 7 & 8 & 9 & 10 \\
\hline Investimentos & 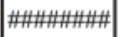 & & & & & & & & & & \\
\hline Receita bruta & & 46.848 .000 & 46.848 .000 & 46.848 .000 & 46.848 .000 & 46.848 .000 & 46.848 .000 & 46.848 .000 & 46.848 .000 & 46.848 .000 & 46.848 .000 \\
\hline Custo de produção & & 36.366 .345 & 36.366 .345 & 36.366 .345 & 36.366 .345 & 36.366 .345 & 36.366 .345 & 36.366 .345 & 36.366 .345 & 36.366 .345 & 36.366 .345 \\
\hline Receita líquida & & 10.481 .655 & 10.481 .655 & 10.481 .655 & 10.481 .655 & 10.481 .655 & 10.481 .655 & 10.481 .655 & 10.481 .655 & 10.481 .655 & 10.481 .655 \\
\hline Impostos e taxas & & 7.360 .097 & 7.360 .097 & 7.360 .097 & 7.360 .097 & 7.360 .097 & 7.360 .097 & 7.360.097 & 7.360 .097 & 7.360 .097 & 7.360 .097 \\
\hline Lucro tributável & & 3.121 .558 & 3.121 .558 & 3.121 .558 & 3.121 .558 & 3.121 .558 & 3.121 .558 & 3.121 .558 & 3.121 .558 & 3.121 .558 & 3.121 .558 \\
\hline Imposto de renda & & 707.204 & 707.204 & 707.204 & 707.204 & 707.204 & 707.204 & 707.204 & 707.204 & 707.204 & 707.204 \\
\hline Lucro líquido & & 2.414 .354 & 2.414 .354 & 2.414 .354 & 2.414 .354 & 2.414 .354 & 2.414 .354 & 2.414 .354 & 2.414 .354 & 2.414 .354 & 2.414 .354 \\
\hline Saldo de fluxo & & -8.594 .746 & -6.180 .392 & -3.766 .038 & -1.351 .684 & 1.062 .670 & 3.477 .024 & 5.891 .378 & 8.305 .732 & 10.720 .086 & 13.134 .440 \\
\hline Taxa de retorno (\%) & & $-78,07$ & $-56,13$ & $-34,2$ & $-12,27$ & 9,65 & 31,58 & 53,51 & 75,44 & 97,37 & 119,3 \\
\hline
\end{tabular}


Análise econômica comparativa de empresas de água mineral quanto ao porte

Tabela 11 - Tabela para o cálculo do Imposto de Renda.

\begin{tabular}{c|c}
\hline Valores do lucro tributável & Porcentagem \\
\hline Até $\mathrm{R} \$ 180.000,00$ & $25 \%$ \\
\hline De $\mathrm{R} \$ 180.000,00$ a $\mathrm{R} \$ 780.000,00$ & $25 \%+12 \%$ \\
\hline Acima de $\mathrm{R} \$ 780.000,00$ & $25 \%+18 \%$ \\
\hline
\end{tabular}

o lucro da empresa aumentem e o tempo de retorno do investimento seja menor e as taxas de retorno maiores. Serão necessários mais investimentos para o aumento da produção.

Para a Empresa de Mineração A\&M, é possível o aumento da produtividade, mas isso elevará os custos de produção, o lucro e a receita aumentarão e, se não houver necessidade de investimentos grandes, o aumento da produção, o retorno do investimento permanecerá rápido e o saldo de fluxo tenderá a aumentar cada vez mais.

A SPAL Indústria de Bebidas deve evitar realizar mais investimentos e deve aumentar a produção, de forma que a receita e lucro sejam maiores, assim o saldo de fluxo aumentaria mais rapidamente e superaria, num prazo menor de tempo os custos de produção.
Mediante isso, é possível concluir que o efeito-escala da produção influi, positivamente, no lucro e no saldo de fluxo da empresa, pois, com o aumento planejado da produção, a razão entre os custos de produção e o lucro líquido diminui, por exemplo, a ordem de grandeza dos custos de produção não é mais de 10 a 20 vezes o lucro líquido. Isto contribui para a lucratividade da empresa, que consegue aumentar, proporcionalmente, seu saldo de fluxo. Porém isso deve ser combinado à injeção de investimentos não muito vultosos e que possam ser retornados em curto ou em médio prazo. Os custos de produção, quando se aumenta a produtividade, também não devem ser demasiadamente maiores que o lucro líquido da empresa, porque isso faz com que a empresa tenha taxas de retorno menores. É necessário, também, que o saldo de fluxo da empresa cresça vagarosamente para superar os custos de produção. Caso contrário, a atividade perde a sua atratividade econômica. O intuito do crescimento do saldo de fluxo é fazer com o empreendimento expanda e seja lucrativo e competitivo no mercado. Logo há a necessidade de um estudo minucioso para que o aumento da produção e seu efeito-escala sejam otimizados em busca da maior lucratividade e das maiores taxas de retorno do empreendimento.

\section{Agradecimentos}

Os autores do trabalho agradecem à empresa MINERGEO Assessoria e Projetos em Geologia e Mineração LTDA.

\section{Referências bibliográficas}

ROSS, S. A., WESTERFIELD, R. W., JAFFE, J. F. Administração financeira. São Paulo: Atlas, 2002. $776 \mathrm{p}$.

SOUZA, P. Avaliação econômica de projetos de mineração - análise de sensibilidade e análise de risco. Belo Horizonte: IETEC, 1995. 230 p.

Artigo recebido em 12/06/2009 e aprovado em 19/02/2010.

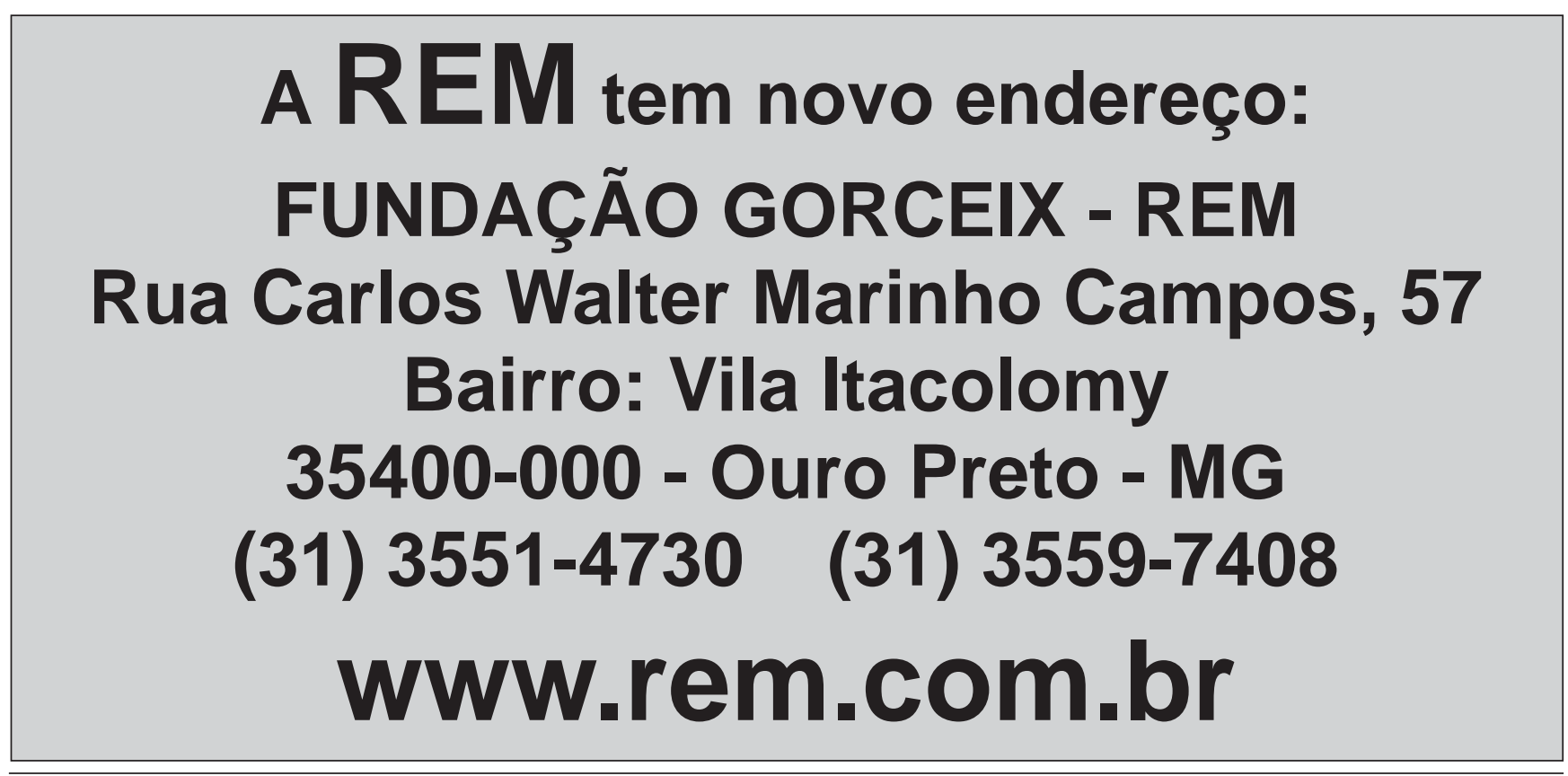

